But even if we admit that Bacon wrote the "De secretis" as we have it in 1248 and was at that time afraid of the Inquisition, the question remains: why in 1267-8, when mentioning the explosive in those works in which he made such desperate efforts to secure the pope as his patron and boasted repeatedly of his own superiority to his contemporaries, did he not claim the credit of the invention which he had set forth in cipher twenty years before? The simple answer is: it was not his invention.

One instance must be added to show how Colonel Hime misinterprets the text of the "De secretis" in his eagerness to smell powder everywhere. He writes (p. 324):

Now, towards the end of Chap. X., Bacon speaks without disguise of charcoal under the name of the wood from which it is made, and mentions the two trees, hazel and willow, which give the best. He significantly adds that when charcoal is added to proper proportions of certain other substances, something noteworthy happens. Since, then, charcoal is one of the subjects of these two chapters, it becomes all the more probable that saltpeter forms another.

In a note Hime adds the Latin of the passage in question:

Si vero partes virgulti coryli aut salicis multarum justa rerum serie apte ordinaveris, unionem naturalem servabunt: et hoc non tradas oblivioni, quia valet ad multa.

Let us note first that these last words do not mean, "something noteworthy happens," but " don't forget this, because it's valuable." Thus the true wording does not in the least suggest an explosion, as Colonel Hime's translation does. Secondly, the words partes virgulti coryli aut salicis probably do not denote charcoal but twigs or rods of hazel or willow, as they do in Bacon's account of the experiment performed by magicians with a split hazel rod. It occurs both in the "Opus Maius" (Bridges, II., 219) and "Opus Tertium" (Little, 49-50; Duhem, 153); I quote the latter.

Unde magici accipiunt virgas coruli et salicum, et dividunt eas secundum longitudinem, et faciunt eas distare secundum quantitatem palmae, et addunt carmina sua, et coniungunt partes divise; sed non propter carmina, sed ex naturali pro. prietate. (Wherefore magicians take rods of hazel and willow, and divide them lengthwise, and hold them the breadth of a palm apart, and add their charms, and the divided parts come together; but not on account of the charms, but from their very natures).

Thirdly, it is probably precisely this hazelrod experiment to which the writer of the passage quoted by Hime refers. Multarum justa rerum serie ordinaveris seems a hurried equivalent for the more specific directions in the passages in the Opus Maius and Opus Tertium, and this bears out what I have already suggested, that the De secretis may be in part at least a brief popular compilation from Bacon's other works. Finally, the phrase unionem naturalem servabunt applies better to the bending together in the middle of two halves of a split hazel rod held apart at the ends than it does to a mixture of saltpeter, charcoal and sulphur.

And now what becomes of Colonel Hime's assertion, "Since therefore charcoal is one of the subjects of these two chapters, it becomes all the more probable that saltpeter forms another"? We may alter it to read thus: since charcoal is not a subject of either of these chapters, it becomes all the more improbable that a method of refining saltpeter is disclosed in them in cipher.

WESTERN RESERVE UNIVERSITY

\section{LyNN ThORNDIKE}

\section{SCIENTIFIC BOOKS}

A Meteorological Treatise on the Circulation and Radiation in the Atmospheres of the Earth and of the Sun. By Frank H. Bigelow, M.A., L.H.D., Professor of Meteorology in the U. S. Weather Bureau, 18911910, and in the Argentine Meteorological Office since 1910. New York, John Wiley and Sons, Inc., 1915. Pp. $x i+431.78$ figures in the text.

This volume is an elaboration of the papers on atmospheric thermodynamics which Professor Bigelow published in the American Journal of Science for December, 1912, and March, 1913, with additions on the laws of storms, on solar constant of radiation, on atmospheric 
electricity, methods of barometric reduction, the meteorology of the isothermal layer, on the laws of evaporation, and a few other subjects to which the author has paid special attention for many years by methods which are often highly original. The book may be regarded as a summation of its author's labors on meteorological theory, and records not a few notable advances in meteorological procedure, especially in regard to the reduction of observations.

To the author of this treatise we already owe the standard system of barometry now used by the Weather Bureau of the United States, an important concatenation of terrestrial meteorological phenomena and solar changes which is here presented anew in slightly revised form, a considerable modification of Ferrel's equations for atmospheric movement in storms with an application to tornadoes which has given, for the first time, reliable data for these very intense movements of the air, and some interesting and highly original, though perhaps not entirely conclusive speculations in regard to the causes of the several variations in the electric and magnetic elements. The present work records a further advance in measures of the ionization of the atmosphere which enable the author to clear up the discrepancy of about 300 per cent. which has hitherto existed between different methods of measuring the dissipation of electricity in the atmosphere.

The special topic around which all the others cluster is the application of the universally accepted thermodynamic equations to atmospheric phenomena. In order to accomplish this, the author is obliged to make the gas coefficient $(R)$ of the usual thermodynamic equations a variable, instead of a constant. It may seem a little risky thus to throw wide open the doors of theory, and to make this fundamental "constant," so-called (whose value has been accurately determined from laboratory experiments) vary through a wide range, while still retaining the form of the equations whose accuracy rests upon these same laboratory experiments. We may ask whether the equations whose accuracy as mathematics is conceded, will continue to be applicable if their basis is changed. More than one meteorologist has suggested to the reviewer that Bigelow seems to be trying to make the laws of nature conform to his equations, with the implication that success in this attempt is somewhat doubtful. It can not be denied that an element of empiricism enters into the proposed methods. The author points out correctly that the well-known departure of the atmosphere from adiabatic conditions is inevitable as long as heat and motion (of air currents) are imported into any given volume of air. This is self evident; but will the thermodynamic equations stand up under this extra burden when the effects of wind and radiation, together with several other activities not explicitly named in this "Treatise," are included? The author claims that everything checks, but on examination this is found to mean simply that when limited to a narrow round of interlocking operations, the numerical work can be performed consistently. On testing the results by comparison with facts which have not been included in the theory, a few discrepancies and inconsistencies are found. An examination of these in detail would extend this notice far beyond the limits of a review and can not be attempted here.

It should be distinctly understood that Bigelow's fundamental equation starts with the thermodynamic equation which has been founded on the behavior of a definite volume of a gas or vapor enclosed in hypothetically non-conducting and impervious walls, when only the internal circumstances of pressure, density and temperature are changed; but in the adaptation of this equation to the free atmosphere, other terms are added which represent infringement of this condition by external interference, and still the process is called "thermodynamic." While an enlargement of the boundaries of this science is desirable, and while perhaps no better way can be found for extending these boundaries than by attending to the experiments which nature performs for us on a gigantic scale, still it must not be forgotten that by this new departure we have slipped our moorings and are at sea on an unknown ocean of many vague possibilities, where the precision of the old 
thermodynamics may not be easy to retain. If this is recognized, then, knowing that meteorology has never been an exact science, there is no reason why this new departure should not be welcomed and thoroughly tested with whatever modifications and improvements may be found necessary; but warning should be given that the terms are now used in a new sense. The present examples go a long way toward supplying such tests. Bigelow's thermodynamics supplements the equally elaborate hydrodynamics of Vilhelm Bjerknes in a muchneeded way. As in all other departments of meteorology, however, the application of the principle is more or less handicapped by the imperfection of the record. A single atmospheric sounding is never completely synchronous, and even if it were, the need remains for connecting the single air column with its surroundings. The importance of a study of cross currents at every level, in both velocity and azimuth, has been shown by Sir W. N. Shaw.

The method introduced in the first part of this work (pp. 262-292) for finding the solar constant, assumes that the reduction of highsun and low-sun observations by the common, but incorrect, hypothesis (that the transmissive power of the atmosphere has no diurnal variation) will give the solar radiation at the 10,000-m. level, but not the radiant value outside the atmosphere; and that an approximately doubled interchange of thermal quantities above the $10,000 \mathrm{~m}$. level (to which the author is led by his thermodynamics) is due to reflection of solar rays from the atmosphere at higher levels; whence the value of the solar radiation outside the atmosphere must be doubled. No one doubts that there is extensive reflection of solar rays by the air. The point to be carefully noted is that these rays can not be both reflected and absorbed. Hence, since any rays which are reflected can have no effect whatever on the thermal state of the substances in question from which the reflection proceeds, this hypothesis also is erroneous. The errors made in these two hypotheses have opposite signs, and it is conceivable that the opposite errors very nearly counterbalance each other, but the procedure is wholly empirical, and any approximation to the truth obtained in this way is accidental.

In spite of the foregoing assumption that all losses of solar radiation above the 10,000 -meter level are by reflection, the seventh chapter introduces considerations of absorption and transmission of solar rays by the various 1,000 meter layers up to $90 \mathrm{~km}$. Though inconsistent with the preceding hypothesis, this move is in the right direction. Unfortunately, however, both here and in earlier parts of this work, some serious errors occur. An extensive footnote (pp. 278 to 280 ) contains the following:

"Transformation Factors.

$$
\begin{gathered}
\frac{\text { kilogram }}{(\text { meter })^{2}}=\begin{array}{l}
\text { Gr. } \times 10^{3} \\
\mathrm{~cm}^{2} \times 10^{4}
\end{array}=\frac{\mathrm{Gr} .}{\mathrm{cm}^{2}} \times 10^{-1} . \\
\left(\begin{array}{c}
\text { M.K.S. } \\
\text { mech. units }
\end{array}\right) \times \frac{10 \times 60}{41851000}=\frac{\text { Gr. cal. }}{\mathrm{cm} .^{2} \mathrm{~min} .} . \\
\text { Factor }=0.000014336 . "
\end{gathered}
$$

The true derivation of the conversion factor for radiant energy from M.K.S. mechanical units into C. G. Min. thermal units is of course:

$$
\frac{1 \text { joule }}{\mathrm{m}^{2} \text { sec. }}=\frac{1 \text { kilogr. cal. }}{4185.1} \times \frac{1}{\mathrm{~m}^{2} \text { sec. }},
$$

which is equivalent to

$$
\frac{10^{3} \text { gram cal. }}{4185.1} \times \frac{60}{10000}=0.0014337 \text { (C. G. Min.). }
$$

The same error is repeated on page 377. On page 415 the author defends his mistake thus: "Since the Erg and the Joule are units of work they must refer to the unit volume and not to the unit area.

$$
\begin{aligned}
& \text { Hence Joule } / \text { volume }=M L^{2} T^{-2} \cdot L^{-3} \\
& =M L^{-1} T^{-2}=10^{3} \times 10^{-2}=10 . \\
& \text { While Joule/area }=M L^{2} T^{-2} \cdot L^{-2} \\
& =M T^{-2}=10^{3}=1,000 . "
\end{aligned}
$$

It is quite true that, for example, the radiant energy received from the sun in 1 second on $1 \mathrm{~cm} .^{2}$ of surface represents the energy previously distributed through a volume of $3 \times 10^{10} \mathrm{~cm}^{3}$; and that, when absorbed by a pyrheliometer, the temperature-effect is determined by the volume of water (equivalent to that instrument) which is heated. But in 
measuring radiant energy by the pyrheliometer, we are dealing with the transition at a surface from radiant to thermal energy. What becomes of the thermal energy afterwardswhether it is distributed to a large or a small volume-does not concern us. The idea of volume is already implied in the definition of the calory which is the thermal effect of a heat unit (equivalent to an equal amount of radiant energy) upon unit volume of water.

The consequences of this mistake are momentous. Whole tables of figures covering several pages have been obtained with this erroneous transformation factor. Other insidious errors may be traced to this misconception. For instance, on page 126 we read: "The Kurlbaum coefficient of the Stefan formula for a perfect radiator is taken at $7.68 \times 10^{-11}$ (C. G. Min. $\left.\mathrm{C}^{\circ}\right)=5.32 \times 10^{-6}$ joules per square meter per sec., so that the air radiates at six times the rate of a perfect radiator in the ether." Six times more than perfection is a rather large order.

In transforming the coefficient in the Stefan Law (on p. 279) by a formula with Planck's constants in C.G.S. units, Professor Bigelow has incorrectly divided by the number of ergs in a joule $\left(10^{7}\right)$, obtaining (p. 280): Sigma $=$ $5.1210 \times 10^{-12}$ in C.G.S. mechanical units, where the exponent should be -5 . His value in M.K.S. mechanical units on this page is sigma $=5.1210 \times 10^{-13}$, which involves an additional error in the logarithmic work. The correct value (after a small change in the adopted basal number), namely, sigma $=$ $5.510 \times 10^{-8}$ (M.K.S.) is indeed given at the bottom of the page, but it has not been used on page 126, where still a new error appears. Evidently, the author's ideas on this subject are considerably mixed.

On page 370 , the energy of solar radiation "used in heating" the atmospheric stratum "above 38,000 meters," is said to be " the true albedo of the earth's atmosphere," which implies that the author has a very obscure idea of what astronomers mean by "albedo." This is surprising, since he has given a correct definition of the word on page 277 .

From what precedes, it results that the nu- merical values of thermal quantities in Tables 84 and 86 , which are said to be in "gr. cal./cm. ${ }^{2}$ min." should all be multiplied by 100 , in which case the sum of the "atmospheric thermal quantities attributable to solar radiation" would not bear the remotest resemblance to the "solar constant," an assumption which is fundamental to Bigelow's entire argument; nor would the so-called "total atmospheric radiant energy" be "equivalent to the 'solar constant' at the distance of the earth" (p. 385), since, even were the equivalence merely one of ultimate derivation, other factors must be considered, for example, the loss of solar radiation by reflection in passing through the air, which does not enter into the thermodynamic equation, notwithstanding the author's assertion (on p. 262) that the albedo of the earth "can be found indirectly by thermodynamic computations."

The summation of atmospheric thermal quantities from the surface to 35,500 meters is said to "give the amounts measured by the pyrheliometer" (p. 379); but the "free heat" $\left(Q_{1}-Q_{0}\right)$ in each 1,000-meter layer, has been stated for unit mass (since the dimensions of heat, work and inner energy are given as $\left[L^{2}\right]$ on page 376 , instead of $\left[M L^{2} T^{-2}\right]$, which requires that both $M$ and $T$ shall be unity), and therefore the numerical values should be multiplied by the density of the layer in transforming them to mass measurement. Moreover, $\left(Q_{1}-Q_{0}\right)$ is due to a flux of long duration and therefore should be averaged, rather than summed, in order to compare it directly with the solar radiation at a given moment. Finally, although neither an average nor a sum of these quantities is exactly equal to the simultaneously exhibited solar radiation, the free heat, though derived from solar radiation, has no immediate connection with the solar radiation at the midday observation to which $\Sigma\left(Q_{1}-Q_{0}\right)$ is incorrectly equated, for it continues by night as well as by day and represents the accumulated result of many days of sunshine, as the writer of this notice has shown in a paper "On the Solar Constant."1

1 American Journal of Science, Vol. XXXIX., p. 201, February, 1915. 
What the thermodynamic computations do show, however, is that the solar effect on the atmosphere above $35,500 \mathrm{~m}$. is nearly as great as that on the lower layers; and this is a fact of very great importance.

The terms " absorption" and "transmission," as applied to the derivation of atmospheric free heat from the sun's rays on page 377 , have apparently been transposed, but are correctly applied as regards terrestrial radiation. This follows because $Q$ is the free heat "transmitted" in a way within the layer, but it is obtained by absorption of radiation and is proportional to such absorption, other things being equal.

The atmospheric heat on which depends the internal radiation of the atmosphere $J_{a}$, given for each 1,000 meters, is equal to the change in its radiant potential $\Delta K$, and is due to absorbed terrestrial radiation. The curve of the change of density with the altitude agrees with that of the $J_{a}$ function, showing that the expansile force of the air, or that force which gives its adiabatic expansion, is wholly governed by the mechanism of internal radiation between the air molecules. $J_{a}$ is largest at the ground surface and progressively diminishes to the outer limit of the atmosphere. The free heat $(Q)$, on the other hand, is distinct from $J_{a}$ and is wholly devoted to expanding the air above the adiabatic rate. While the summations of the two from the surface to about $31 \mathrm{~km}$. are very nearly equal, their distribution is quite different. $Q$ is very small in the lowest layers and increases upward, but with wide fuctuations. In a general way $Q$ follows the fortunes of the incoming solar rays, and while it may not be wholly dependent on their absorption, it appears to be very nearly so. There is no evidence that the curve of density agrees with the solar radiation at every level, as is asserted in Chapter VII.

If the air radiated like a black body, the radiation $J_{0}$ of any layer could be computed from the temperature by Stefan's Law. Summed, layer by layer, for the air column up to $50 \mathrm{~km}$., $\Sigma\left(J_{0-1}-J_{0-0}\right)=-381.81$, while $\Sigma\left(J_{a_{-1}}-J_{a_{-0}}\right)=-136.75$, or the air radiation is about one third that of a black body. The figures, as thus stated, denote a thermal transference of so many gram calories per minute within a volume of five million cubic centimeters, and are derived from Bigelow's computation after correcting for the erroneous transformation factor; but they lend no support to his curious conclusion that air radiates six times better than the black body.

The pyrheliometric method for finding the solar constant which is described in Chapter V., is further extended and modified in Chapter VII., pages 388 to 394 . This method is finally admitted to be discredited by experience, though its author does not recognize why this is so. A new and entirely different method of discussing pyrheliometric data is then developed (pp. 394 to 401) which, though empirical, appears to eliminate the influence of water vapor and altitude in the general means very well, making it possible to compare winter observations with summer, and also to determine a station correction to sea level. In this method the erroneous data derived from incorrectly interpreted thermodynamics are abandoned. The extrapolation of the resulting curve $(A$, Fig. 76) gives solar radiation $=3.22$ at the height for which the writer's reduction of Violle's high-level observation gave 2.86 gram cal./cm. ${ }^{2}$ min.; and thus it appears probable that the value which Bigelow adopts for the solar constant (3.95) should be reduced to 3.6 gram cal. $/ \mathrm{cm}^{2}{ }^{2}$ min. A similar result follows from the writer's interpretation of the thermodynamic argument.

The formula for the mass of aqueous vapor in the upper air (pp. 342 and 373) is both complicated and erroneous. It gives a value about three times too large at 10,000 meters, ten times too large at about 24,000 meters, and increasingly greater at still higher altitudes.

The author's faith in the virtues of a formula is seen in his publication of some columns of figures which make such well-recognized constants as the mass of a hydrogen atom and the charge on an electron, variable. There are a few minor mistakes, such as the conversion of the charge on an electron through the use of an erroneous dimensional formula, but these will be readily recognized. 
The work under review is one of extremes. It ascends to heights of excellence and brilliant achievement, and then breaks down, where one would least expect it, in errors and fallacies which seem inexcusable in one so gifted. It is greatly to be regretted that a book involving so much original work, and containing so much that is really valuable, should be marred by blemishes which prevent it from being regarded as an authority. Nevertheless, if the judicious reader will pardon these blemishes, the larger part of this treatise constitutes a monumental work of great erudition, and of elaborate and industrious research.

\section{Frank W. Very}

The International Rules of Zoological Nomenclature, with Appendix and Summaries of Opinions No. 1 to No. 56. T. O. SMallwoop, $3216 \mathrm{~N}$ St., Washington, D. C., September, 1915. 4to. $28 \mathrm{pp}$.

The ninth International Congress of Zoology met at Monaco, March, 1913. The full report was issued by the Imprimerie Oberthur, Rennes, France, 1914. Owing to the disturbances in Europe this report is practically inaccessible to students, and no separate copies of the rules in English appear to be available, nor does any provision seem to have been made for the republication of the rules separately. Hence the publisher of this pamphlet, with the approval of the secretary of the International Commission and the careful supervision of some of the American members, has provided what may be regarded as a trustworthy edition which may be obtained as above indicated.

A partial reprint of the rules without the opinions has been issued in French by M. Maurice Cossmann in the Revue critique de Paléozoologie for July and August, 1914, and in this connection a word of caution seems to be required. On page 14 of the separate copy of this rendition of the rules we read as follows under the following caption:

\section{Autres Décisions du Congrès se Rapportant à la Nomenclature}

$A$. Des exceptions à la loi de priorité pourront être admises: $1^{\circ}$. Quand un nom de Genre ou d'espèce devrait être transporté à un autre Genre ou à une autre espèce existants;

$2^{\circ}$. Quand un nom a été employé pour un Genre pendant 50 ans, jusqu'à 1890 , dans les travaux scientifiques, tels que monographies, catalogues scientifiques, etc.;

$3^{\circ}$. Quand le nom le plus ancien, conformément à la loi de priorité, n'a pas été admis pendant 20 ans dans la systématique scientifique.

Note.-Chaque exception doit être soumise à la Commission internationale de Nomenclature qui examine chaque cas et le soumettra au prochain congrès international.

As the title of the pamphlet reads " Règles internationales ... Adoptées par les Congrès," etc., it would seem that the reader might readily suppose that the paragraphs quoted from M. Cossmann's reprint (but not appearing in the English version) had been affirmatively decided by the congress. This, however, is not the case. Paragraphs $A 2$ and $A 3$ were submitted, it is true, but were definitely rejected, though no indication of this appears in the French reprint. Paragraphs $A$ and $A 1$ are qualified by the note under paragraph $A 3$, each case to be submitted to the commission and decided on its merits.

WM. H. DALL

\section{SPECIAL ARTICLES}

THE LIGHT-SENSIBILITY OF COPPER-OXIDE

THE fact that selenium changes its electrical conductivity under the influence of light was discovered by May in 1873 . Since that time the property of light-sensibility has been looked for in many substances and it has been found that sulphur, shellac, paraffin, anthracene and several other substances possess this property to a slight extent. The most noteworthy addition to the list was made by Jaeger who discovered the light-sensibility of stibnite (native $\mathrm{Sb}_{2} \mathrm{~S}_{3}$ ) in 1907. Since a careful study of the behavior of these substances is bound, ultimately, to shed light on the mechanism of metallic conduction, it seemed worth while to continue the search for other substances which show marked light-sensitiveness. Recently the 